\title{
A STUDY OF THE LIFE-HISTORY AND HABITS OF CHÆTOPTERUS VARIOPEDATUS, RENIER ET CLAPAREDE.
}

\author{
HOWARD EDWIN ENDERS.
}

With Three Plates.

\section{INTRODUCTION.}

While I was at Beaufort, North Carolina, during the season of 1903, I became interested in the peculiar modifications that adapt Chætopterus to its sedentary mode of life. At the suggestion of Dr. E. A. Andrews I undertook to study its embryology and anatomy the following season, but was unable to rear the larvæ beyond the stages which E. B. Wilson has described. Toward the end of the season of $1905 \mathrm{I}$ was successful in rearing larvæ from eggs to such a stage that it was possible to know the younger larvæ collected in the towings. I was fortunate enough to find a sufficient number of Chætopterus larvæ in the towings to observe the important stages in the lifehistory and to rear the younger ones in the aquaria. In a brief time they grew to stages that correspond with the young worms on the sand flats. I have now two worms living in the laboratory of the Johns Hopkins University that grew from larvæ taken in the townet more than ten months ago.

The muscular movements of the older larvæ were so strong and rapid that it was impossible to make projection drawings of them. Narcotization was unsatisfactory, so they were drawn by the aid of measurements made with a micrometer eye-piece.

I have sectioned some of the larvæ, but the number of specimens is insufficient for a complete study. I hope to present the results of a histological study of Chætopterus in a later paper.

The .Journal of Morphology.-Vol. XX, No. 3. 
The presence of hundreds of Spiochatopterus larvæ, which, in the younger stages, resemble the younger larvæ of Chætopterus, confused me for two weeks until I permitted several of each genus to settle down and complete their transformation. When this was completed I discovered that the majority of the transformed individuals were Spiochætopterus.

The fertilization and segmentation of the egg has been described by Mead, and the free swimming young have been described by Wilson, therefore these subjects will be passed over briefly. My own description will have reference to the transformation and development up to the period at which the definitive characters of the adult form have begun to appear. In order to properly interpret the transformation I shall take up the adult morphology before dealing with the embryology.

In my study of the adult worms I have verified J. Joyeux-Laffuie's monograph on Chætopterus but will here describe chiefly such parts as will aid in understanding the transformation of the larva. Throughout the paper I have usually used Laffuie's nomenclature for the adult and also for the larva.

The work, of which the present paper is an account, has been carried on in the Zoological Laboratory of the Johns Hopkins University, and in the Fisheries Laboratory at Beaufort, North Carolina.

I am indebted to Honorable George M. Bowers, United States Commissioner of Fish and Fisheries, for the privilege of occupying a table in the Fisheries Laboratory at Beaufort, North Carolina, and to Dr. Caswell Grave, Director of the Laboratory, for many privileges extended. To Dr. E. A. Andrews, of the Johns Hopkins University, I am indebted for valuable suggestions in the work. I desire to express my thanks to Mr. Charles Hatsell of Beaufort, North Carolina, for specimens of living Chætopterus, which he collected and sent me during the winter of 1905 .

To Professor Brooks I express my hearty appreciation of his interest and friendly counsel in the direction of my work.

Chotopterus variopedatus, Ren. et Clapd., is a widely distributed tubiculous annelid of the family Chætopteridæ. The individuals of each country and of widely distributed areas in Europe were 
classified as distinct species, but Joyuex-Laffuie, '90, showed that the nine European species are really a single species. He also suggested that a close study of the six species in foreign seas would yield a similar result. Later, Græffe, '05, mentions Chotopterus pergamentaceus, Andouin et M. Edwards, the name by which the American species has been described by Verrill, E. B. Wilson, and others, as synonymous with Chatopterus variopedatus. A careful comparison of the specimens found at Beaufort, with Joyeux-Laffuie's description of $C h$. variopedatus leads me to regard the species as synonymous.

The characters are briefly as follows:-Anterior region is composed of eleven segments of which nine are setigerous. Middle region, five segments. Posterior region, segments numerous, but variable to fifty.

Buccal funnel large, forms the anterior part of the body. Tentacles two, conical, lateral 8-12 mm. Eyes two, just lateral to base of tentacles, brownish. Nine setigerous segments are notopodia, conical, lateral and with a thickened plastron between on ventral side; setæ lance-shaped, some in fourth setigerous segment black, club-shaped, truncate. Pair of epaulet-like structures at posterior margin is neuropodia, armed with serrate uncinal plates.

Middle region.-Composed of twelfth and thirteenth segments and three palettes. Twelfth segment bears long aliform notopodia on dorsal side and adhesive disc on ventral. Thirteenth segment, the accessory feeding organ above and adhesive disc on ventral side of second and third. Dark green dilated intestine on dorsal side between twelfth segment and first palette (fourteenth segment).

Posterior region.-Segments decrease in size regularly backwards-variable from 2, 3 or 4 in young to 500 in old individuals. Each bears a pair of conical notopodia directed dorsalward, a pair of internal lobes and a pair of external lobes on the ventral side of the body. External lobes with cirrus. Anus dorsal.

Color.-Transparent yellowish-white anterior region; middle dark green about intestine; posterior, reddish-yellow in females, white in males.

Tube.-U-shaped, opaque parchment-like, white annulated ends, dirty yellow in horizontal and vertical portions, covered with grains of gray sand. Orifices diameter 1 to $7 \mathrm{~mm}$. Length of the tube $18 \mathrm{~mm}$. to $50 \mathrm{~cm}$. Width of tube $1 \mathrm{~mm}$. to $4 \mathrm{~cm}$. Length of worm $1 \mathrm{~cm}$. to $30 \mathrm{~cm}$.

\section{Habitat-Collecting-Morphology.}

Chcetopterus variopedatus, the peculiar species of sedentary annelid, upon which the following study has been made, is found in several localities in the harbor of Beaufort, North Carolina, where the conditions for its existence are afforded by the extensive sand-flats, 
either covered with a thick growth of diatoms or continually exposed to currents of water heavily charged with diatoms. It is here found living within its broadly U-shaped parchment tubes in nearly every portion of the harbor wherever the sand-flats are formed in the quieter waters. It is less abundant on the tide-swept flats of coarse sand, and so far as I know it has never been taken during any of the dredgings in the channels; this may be due to the rapid changes in the shifting channels within the large but shallow harbor.

The shallow water in which the worms live here is in marked contrast with their position along the coast of France where JoyeuxLaffuie procured the animals either by dredgings in water ten meters deep or from among the masses of tubes cast upon the shore after the great storms from the north and northwest. Along the coast of France the annelids are confined to the deeper water on account of the shifting sands of the shore, but on this portion of the American coast an abundance of material may be collected with a spade at a single low tide. At Beaufort, during three summers, I found only two mutilated tubes cast upon the shore outside of the harbor after heavy storms. It is rather more likely that these tubes were carried out from the harbor than that they were torn up from the deeper regions beyond the harbor.

The presence of Chætopterus may be recognized at low tide by the two extremities of the broadly U-shaped tubes that usually protrude several centimeters above the level of the shoal (Fig. 1). The extremities of some tubes are concealed by ascidians, colonies of bryozoans, or of hydroids, attached to them so that it may be difficult to detect their circular whitish openings within the cluster of attached animals. Usually two tubes are visible above the surface of the sand, but three are frequently found, as I shall show later (Fig. 2). After both extremities, which are from fifteen to fifty centimeters apart, have been located, it is a very simple matter to remove the tube by simply raising it with a spade and then gently freeing it from the wet sand. Where the three tubes are present the third may be overlooked and the animal may be mutilated in removal.

The animals may be removed from the tubes in perfect condition by ripping them lengthwise with one's fingers. The habit of the 
animal to shrink to one end of the tube makes it difficult to remove it without danger of injury when any sharp instrument is used.

When the tube is opened the animal is found attached to the inner wall by three adhesive discs. These are on the ventral side of three successive segments posterior to the region of the body which is frequently mistaken for the "head," but which is the anterior region of the body fused with an inconspicuous head.

The most noticeable features in the worm are the extreme delicacy of its tissues and the great diversity in the form of its segments. They are so much unlike those found among others of the polychæte annelids that it would seem, at first sight, to be impossible to show the homologies between the different regions. This, however, has been done by Joyeux-Laffuie.

Chrtopterus, like all the other polychæte annelids, is made up of a number of segments which varies considerably with the age of the individuals. There is, withal, such a similarity among the segments in several portions of the body that they may be considered in three groups, as Joyeux-Laffuie has done. The anterior region consists of eleven segments (based by Laffuie upon the study of the nervous system) of which the last nine are setigerous segments. The middle region consists of five segments and the posterior region has from two, in the youngest individual, to fifty in the largest specimen.

The dorsal side of the body (Figs. 3, 4 and 5) may be distinguished from the ventral by the presence of the very evident ciliated groove which arises directly back of the dorsal lip of the buccal funnel and extends to the mid-dorsal line of the first segment of the middle region. It also bears a pair of tentacular cirri at the anterior end of the superior region, and large aliform appendages on the first segment of the middle region (12th segment). The fourteenth, fifteenth and sixteenth segments ( $3 \mathrm{~d}, 4$ th and 5 th in middle region) have the form of palettes, but each of the segments of the posterior region bears a pair of conical notopodia which are directed dorsalwards.

The ventral (Fig. 6) side is broader and more muscular in the anterior region than any other region of the animal. The ventral side of the fourth setigerous segment (6th segment) bears black clubshaped setæ, which give this region of the body the appearance of 
bearing "eyes." The pair of dorsal longitudinal muscles common to many of the annelids is lacking in Chrotopterus, but a pair of thick longitudinal muscles is conspicuous over the middle region. Each of the three foremost segments of this region bears a more or less shieldshaped disc. The posterior region bears a pair of external lobes of the parapodia which diminish progressively in size to the anal segment.

The anterior region.-The anterior region is firmer, somewhat more opaque and more muscular than the remaining regions of the body. Through its transparent dorsal surface are seen the septa which correspond in number with the nine conical dorsal rami on each side of this region. Its outline is better described as a tall trapezoid than as a parallelogram, as Laffuie does. I would also differ from this author in regard to the dorsal and ventral surfaces, which are convex. In cross-section this region is elliptical in outline. (Fig. 15.)

The mouth of the adult is at the forward end of the anterior region. It is surrounded ventrally by a broad flattened lip which is continued dorsalward on each side in the form of an auriculate appendage that overlaps the base of the tentacle of the same side. On the whole it forms a broad funnel which is incomplete on its dorsal side. The mouth is bounded dorsally by a thickened edge whose anterior margin may be a rectilinear line transverse to the axis of the worm, or it may at times form an obtuse angle with the auriculate appendages of the ventral lip. Its form is dependent upon the activity of the living animal, and the form assumed in the preserved specimens does not well represent it.

A pair of slender conical tentacles is located on the dorsal side of the mouth immediately back of the thickened dorsal lip. At the lateral margin of the lip the dorsally-directed auriculate lobes of the ventral lip of the buccal funnel cover the base of each tentacle. They bear a groove on their inner margin which is covered with a ciliated epithelium as Laffuie says. In Spiochætopterus the tentacles are as long as the body of the worm and the ciliated grooves function as important accessory feeding organs.

The nine setigerous appendages are conical structures arranged at the lateral margin of the anterior region. When they are extended 
their length is half the width of the plastron and the diameter of the base half the length of each appendage. Together with the broad plastron they either form a plane, or the whole may be directed dorsalward at the margin so that a cross section would be crescentic in outline. The integument of the dorsal side of the appendages is more transparent than in any other portion of the anterior region and the setæ with their protractor muscles may be seen through its transparent walls. The setæ are arranged in the form of a fan. Their lanceolate ends protrude in a line along the ventral side of each of these rami and are directed laterally along the rami. The ventral setæ of the fourth setigerous segment are black and somewhat clubshaped at their external ends. Their shafts are thick and bear annulations which are not detected in the slender shafts of the lanceolate setæ. The number of setæ varies with the age of the individual. I have found as few as five in each parapodium in a young individual to ninety in an adult specimen of average size.

The first pair of setigerous appendages is located just beneath the dorsally-directed ends of the ventral lip of the mouth. It is considerably smaller than the other parapodia, which increase progressively to the ninth pair. These conical appendages are regarded by Jourdain as the dorsal rami of the parapodia, and the somewhat triangular epaulet-like appendages of the ninth pair he regards as the ventral rami of the parapodia.

The ventral surface of the anterior region consists largely of a yellowish to a reddish yellow granular area surrounded by a narrow border of lighter color. It extends around the whole ventral surface of the anterior region encircling the ventral lip and extendirig between the rows of dorsal rami on each side and the yellowish "plastron" just described. In section the plastron consists of long columnar cells of ectoderm (Figs. 15, 16).

The dorsal surface of the anterior region bears a ciliated groove (Figs. 5, 15-18) which extends in a middorsal line from a point just behind the thickened rim of the dorsal lip of the buccal funnel, to the middle of the first segment (twelfth of the whole animal) of the middle region. At this point it diverges to the right and to the left along the large aliform appendages. It functions as an important accessory feeding organ, as I shall show. 
The "eyes" of the adult are frequently overlooked, but they were clearly pointed out in Laffuie's monograph. One black eye-spot is located on each side external to the antenna and directly beneath the dorsally directed auriculate lobe of the ventral lips of the buccal funnel. It is here less conspicuous than in the larva. The dorsal eyes of the larva are not demonstrable in the adult individuals.

The middle region.-The middle region is situated immediately back of the ninth setigerous segment, and communicates with it by a narrow cylindrical region little thicker than the ventral muscles themselves. It is conspicuous because of the diversity in the form of the segments and for the dark green color of the intestine as seen through the transparent integument which covers the dorsal side of the body.

The number of segments in this region of the body is disputed by various workers. De Quatrefages and Jourdain include the twelfth segment, with its large aliform notopodia, in the middle region, but Laffuie accepts the former view "as being the most natural." More recently (1897) Ray Lankester published a figure in which he includes the twelfth (his eleventh) segment in the anterior region, but it may have been drawn in conformity with the views of Lespes and Cosmovici. My observations upon the extent of the œsophagus and its transition into the dilated green portion of the gut, both in the adult and the transforming larva, confirm the opinions of Laffuie and Jourdain. I shall, therefore, regard the twelfth segment as a part of the middle region, which is made up of five segments. Of these the last three segments have the form of "fans" or "palettes," and consist, according to Laffuie, of the fused notopodia and neuropodia of their segments. The thirteenth segment (second of the mid-region) is usually described as consisting of a ventral and a dorsal sucker, but I shall call the "dorsal sucker" or "dorsal cupule" an accessory feeding organ for reasons that follow in another chapter.

The twelfth segment (first of the middle region) on the dorsal side bears a pair of large flattened aliform notopodia. When they are extended at right angles to the long axis of the worm their outline forms a tall isosceles triangle whose base joins the walls of the body. The distal fourth of their dorsal margin bears a small spatu- 
late plane surface at right angles to the plane of flattening of the notopodia. A complicated ciliary furrow on each notopodium extends from the proximal end of the spatulate surface along the dorsal margin of the notopodium, to a mid-dorsal position where each meets the furrow from the opposite side. At this point these furrows unite with the furrow from the anterior region. The worm, when the tube is opened, is frequently found with its aliform notopodia bent obliquely forward and dorsalward till the spatulate surfaces join. The large open arch thus formed brings the eiliated furrows into the inner border of the arch where it can serve most effectively as an organ for collecting the food. This function will be referred to in a later paragraph on the feeding habits.

The aliform notopodia are strengthened internally by the presence of numerous straight, slender setæ which do not protrude to the exterior except in specimens that have begun to macerate. They are arranged parallel to one another and oblique to the long axis of the appendage. The ventral rami, or neuropodia, of the twelfth segment, are fused to form an elliptical adhesive dise which is concave ventrally. It, together with the adhesive dises on the ventral side of the next two segments, attaches the animal to the inner wall of the tube. In form and size the disc of the twelfth segment agrees with the adhesive disc of the thirteenth segment, therefore the description of one will answer for the other. The long axis of both adhesive dises is equal to or greater than the width of the plastron of the superior region and the width is equal to about half the length. They bear, along their free anterior and posterior edges, numerous brown uncinal plates with serrate edges, as has been well described by Laffuie in tracing out the homologies of the parapodia. Of the structure of these small saddle-like ventral suckers or adhesive dises Laffuie says (page 261): "The fusion is indicated by a median furrow which presents a little depression toward its middle." This is especially true for the adhesive disc of the fourteenth segment (third of the mid-region), but it is not observable in the large adhesive dises of the twelfth and thirteenth segments. Just dorsal to the adhesive dises are the two large ventral muscles. They extend aiong the ventral side of the mid-region from the epaulet-like neuropodia of 
the eleventh segment in the anterior region through the twelfth and thirteenth segments as large parallel cylinders. The dilated green intestine rests upon their dorsal side.

The thirteenth segment (second of the mid-region) includes all that portion of the animal between the twelfth segment and the first palette. When fully extended it may be as long as the whole anterior region. In the middle of its ventral side is found the adhesive disc mentioned and described above, as setting like a small saddle over ( $i$. e., beneath) the ventral longitudinal muscles. It communicates laterally by two yellow strands of tissue, continuations of the body cavity, with Laffuie's "dorsal cupule" in such a manner as to suggest a "two-collet ring" about the worm. I shall, provisionally, name the "dorsal cupule" the accessory feeding organ of the second mid-segment. On the anterior half of the dorsal side is the greatly dilated light green portion of the intestine. During life it is marked here and there by purse-like swellings which are in constant rhythmic motion from before backwards. The posterior half of the dorsal side consists of the convoluted portion of the conspicuous green intestine, whose whole surface is traversed by peristaltic waves.

Upon the dorsal side and about the middle of the segment is situated the hollow muscular accessory feeding organ which was mentioned above. It has the form of a cowl or hood which opens dorsally (Figs. 2, 3, 5 and 7). Its smaller open end is joined by a narrow pedicel to the two diverging, tubular portions of the bodycavity which unite to the ventral adhesive disc and thus give to the whole the general aspect of a "two-collet ring." From the pedicel of this structure a solid strand of muscle extends anteriorly over the dorsal surface of the intestine to the base of the twelfth segment. Cosmovici's view that this was a continuation of the ciliated groove of the anterior region was plainly shown to be erroneous. When the ventral muscles contract the dorsal strand also contracts and causes the accessory feeding organ to be raised vertically or tilted forwards (Figs. 3 and 4) so that it takes a position somewhat within or immediately back of the arch which is formed by the joined aliform notopodia of the twelfth segment. The accessory feeding organ bears gland cells scattered over its outer surface, but the inner surface bears a ciliated epithelium. 
Laffuie is probably correct in giving the homology of this accessory feeding organ as follows: "The dorsal sucker (cupping-glass) formed by the terminal portions of the two dorsal rami united in the median line, is rounded externally and hollowed out internally into a deep cavity. Longitudinal and transverse sections clearly show its structure. The wall is double and the space comprised between the two walls is a diverticulum of the general cavity." My observations, which are based on dissection and sections, verify his observations that the wall is double and that the space between the walls is a diverticulum of the general cavity. Numerous muscle strands join the inner and outer walls of the pouch to one another. In regard to the function of this accessory feeding organ Laffuie says (page 264): "This dorsal cupule functions as a true sucker and enables the animal to adhere to the inner wall of its tube. This is easily verified by carefully removing a few Chrtopteri from their tubes. This sucker is the only part situated upon the dorsal surface which could be used for holding the animal in its tube." I never once, among more than two hundred specimens, observed the structure in use as an attaching organ, but I have frequently observed that in some individuals it contained a greenish mass of diatoms and other organic matter mingled with mucus. The presence of nutritive material in this pouch led me to search first for a direct communication with the intestine at this point in order to acount for the presence of this mass of food so far removed from the mouth. The introduction of finely divided particles of carmine in sea water into the pouch at once demonstrated a strong ciliary current running directly or obliquely from the margin to the deeper portion of the pouch. Here the particles were rotated for some time, but they were later discharged from the pouch in a manner that will be taken up in the next chapter.

Fourteenth, Fifteenth and Sixteenth Segments.-The fourteenth, fifteenth and sixteenth segments together are somewhat shorter than the anterior region, but when the animal is extended they occupy nearly half of the middle region of the body. They form a series of very muscular campanulate organs, each with its base directed forward. One side lies against the ventral longitudinal muscles from which they derive the muscle strands that make them effective 
"fans." The fans exhibit a continual rhythmic movement that usually sweeps the water towards the posterior end of the animal. On account of their similarity in nearly every respect a description of one of the segments will answer for the remaining ones.

The fifteenth segment (fourth of the mid-region), when in the middle of a beat, has the form of a broad bell. Its base, which is directed toward the forward end of the body, is covered with the delicate integument of the body. At some distance from and parallel with the periphery of the bell the integuments of this base are joined to the integuments of the top (i.e., posterior convex portion) by means of delicate cross-strands of muscular tissue. This produces on its anterior surface a shallow semi-circular furrow that is parallel with the edge. The cavities which are found within the bell are diverticula of the general cavity. Within the central portion is seen the greenish tinted sigmoid curve of the intestine, and in the lateral cavities are seen the vesicular portions of the third pair of nephridia. The ventral side of the "bell" rests with its whole length upon the ventral longitudinal muscles in such a way that its rim surrounds these muscles ventrally. Immediately posterior to this rim and in the middle of the segment is a pair of thick spatulate appendages which are directed posteriorly. The presence of several close-set rows of brown uncinal plates on the distal margins of these neuropodia, and an additional pair of small papillæ, which bears uncinal plates, near the ventral margin of the bell, confirms Laffuie's conclusions on the homology of these segments with the other segments of the body (page 267): "This papilla represents the external lobe of the ventral ramus and is homologous with it. It is consequently the homologue of the superior edge of the ventral suckers of the twelfth and thirteenth segments." "The central part of the palette represents the body of the animal, while the peripheral part is the homologue of the ventral rami, rami which are fused to the walls of the body by their inner face."

The fourteenth segment (foremost palette) bears a small adhesive disc of the same form as those of the twelfth and thirteenth segments. It is intermediate in structure between these and the large neuropodia just described for the palettes. That it is homologous 
with the internal lobes of the neuropodia is indicated by uncinal plates at its posterior margin alone. The external lobes are represented by small papillæ on the margin of the palette.

Posterior region.-The posterior region consists of the segments between the sixteenth and the anus, which is on the dorsal side of the terminal segment. The number, which varies considerably with the age of the individuals, I have found from two, in a very young specimen about one centimeter long, to fifty in an adult about thirtytwo centimeters long when extended. Since the segments are identical in form, but in size they diminish progressively to the anus, the description of a single segment ( $e \cdot g$., the nineteenth segment) will suffice for this whole region. The course of the intestine appears as a greenish trail over the whole dorsal side.

When the animal lies in its normal position in the tube the lateral sides of the segment expose a pair of swaying conical notopodia whose distal ends are directed vertically upward or obliquely outward from the mid-dorsal line of the body. When filled with the sexual products they are opaque, at other times transparent. Toward the anal segment, however, these notopodia are directed more and more laterally till finally the last few pairs extend out horizontally and may be directed posteriorly. Through the transparent integument of the notopodia may be seen a bundle of straight slender setæ of which no portion extends to the exterior in fresh specimens. In mature males during the breeding season the cavities of the notopodia are completely filled with sperm which gives this region a milky white appearance (Fig. 4). The eggs, which float in the general cavity, and the convoluted ovary give the sexual segments of the females a roseate yellow tint. On the posterior (inferior) surface near the base of each of the notopodia, $i$. e., between the notopodia of adjacent segments, are located the nephridiopores. Each has the form of a slight transverse slit in a small elevated area (Fig. 8).

The ventral aspect of a segment is complicated through the presence of a pair of median (internal) and a pair of lateral (external) lobes of the neuropodia (Figs. 6 and 8). The internal lobe has the form of a cylinder which is slightly flattened antero-posteriorly. It is united along a portion of its mesial side with the adjacent lobe 
of the same segment. The free distal margins bear a row of uncinal plates. They have already been pointed out in the homologous structures: the posterior margins of the adhesive dises, the similar but larger spatulate neuropodia of the mid-region, and the epauletlike appendages of the eleventh segment (last of the anterior region). The external lobes of the neuropodia are situated just lateral to the internal lobes, so that a narrow cleft exists between their bases. These lobes are larger than the internal lobes. In form they resemble a greatly thickened broad-ax whose head forms the thick pedicel (Figs. 6 and 8). Its free edge lies on the same plane with the segment but it is directed obliquely outward from a mid-ventral line. The edge bears a row of uncinal plates and has been homologized by Laffuie with the same patches of uncinal plates on the fourteenth, fifteenth and sixteenth segments, and to the anterior margins of the adhesive dises of the twelfth and thirteenth segments. The outer edge of the external lobe bears a slender conical cirrus in whose cavity the sexual products of ripe individuals may be seen by transparency. The form and the tint of the branches of the parapodia vary greatly with the turgor.

The nephridia have been mentioned only incidentally. As pointed out by Laffuie, the first pair of nephrostomes occurs in the twelfth segment (first of the mid-region) and the nephridiopores open to the exterior in the succeeding segment. Each segment back of this, except a few terminal ones, bears the nephridiopores of one pair of nephridia and the nephrostomes of the succeeding pair. The nephridia of the segments back of the sixteenth serve both as organs of excretion and for the discharge of the sexual products.

The sexually mature males and females may be distinguished with ease by the color of the sexual products which in the posterior region fill the body cavity and its diverticulæ. The males appear milky white and the females are more yellow or roseate yellow. The eggs can be seen surging about with the general movements of the body. Adults that have discharged their sexual products can still be distinguished by the same characteristic colors of the more slender convoluted testes or ovaries, but the segments are more transparent. The sex of immature or young specimens can not be distinguished by any difference in color. 
The Digestive Tract.-The digestive tract of the adult Chætopterus forms a comparatively straight tube except in the middle region of the body where it forms several convolutions. Its greatest diameter is reached in the middle of the body, but in the posterior region it diminishes slightily in calibre.

The large mouth and broad buccal funnel have been described as being located at the anterior end of the anterior region. At the inner end of its dorsal lip the mouth communicates with a tubular esophagus which is usually flattened from right and left sides so that, in sections, its lateral walls lie parallel and nearly touch one another. The flattening is produced chiefly by the presence of the muscular partitions of the setigerous segments. The flattened esophagus occupies nearly the whole dorso-ventral space within the anterior portion of the anterior region (Fig. 15). Throughout the posterior portion of this region it is circular or elliptical in transverse sections. Posteriorly, and in the vicinity of the ninth setigerous segment, the esophagus becomes dilated considerably so that it becomes tubular. Here it becomes differentiated into a glandular and a ciliated epithelium (Fig. 16). The epithelium of the ventral half of the esophagus consists of tall, ciliated columnar cells whose nuclei lie at their free ends. In this respect the cells are like those in the middle and fore parts of the esophagus and the buccal funnel. In its dorsal half the epithelium of the esophagus is thrown into folds. Many of its cells are glandular. The nuclei are located toward their proximal ends. The glandular portion begins in the dorsal wall of the esophagus immediately back of the ninth setigerous segment as a small group of cells. It gradually spreads out so that it occupies the dorsal half of the esophagus (Fig. 17) at a point midway between the posterior border of the ninth setigerous segment (eleventh of the anterior region) and an imaginary line joining the bases of the notopodia of the twelfth segment (first of the middle region). Immediately anterior to the bases of these notopodia the glandular portion ends blindly as a small cylindrical sac which lies dorsal to and parallel with the esophagus (Fig. 18). Within the lumen of the glandular portion, whose length is about equal to that of the cylindrical fæcal masses discharged by the 
animal, occurs a layer of mucus (?) that is stained in the sections. I shall have occasion to refer to this structure in the chapter on Habits and Physiology. The esophagus, or a continuation of it, extends through the middle portion of the segment, $i$. e., the portion bearing the large aliform notopodia, as a convoluted tube of diminished calibre. Directly back of the aliform notopodia it lies for a few millimeters in the median plane of the animal, and its posterior end extends as an invagination into the large, dilated green portion of the intestine with which it is continuous. Sections through this region show two concentric layers of epithelium: an inner layer of ciliated cells and an outer layer of cells filled with green granules.

The conspicuous dilated green portion of the intestine is confined to the thirteenth segment. Its anterior half consists of a thin-walled dilated sac, but it becomes constricted where it passes beneath the accessory feeding organ of the thirteenth segment. In the posterior half of the segment it again becomes dilated. This darker portion forms two and one-half convolutions in a horizontal plane before it reaches the fourteenth segment (the first palette). In the palette the intestine has a smaller calibre but it is still seen by transparency as a dark green tube. In the intervals between the palettes it is considerably constricted, but it again becomes dilated within each palette where it makes a siphonal curve in a dorso-ventral plane and then passes into the posterior region of the annelid. In the posterior region it is less green in color. When the animal is extended the intestine appears as a slightly sinuous tube of gradually diminishing calibre. Its constriction and dilatations correspond with the septa and segments it traverses. It opens to the exterior by the large gaping anus located dorsally at the posterior end of the animal.

Claparede described the pigmentation of the epithelium of this middle region of the body in his Annelides sedentaires (1873). Its distribution has since been correctly described by Joyeux-Laffuie ('90) and by Ray Lankester (Benham's observations, '97). It is distributed in the epithelial cells of the intestine in the form of spherical granules of varying size. They are embedded in the protoplasm of some of the cells in such numbers as to give the cells an irregularly distributed green color, as seen in section, with moder- 
ate magnification. The presence of large globular goblet-cells confirms Benham's observation that the elongated ciliated cells which contain the green granules are associated with gland cells.

The pigment of the intestinal wall has received different names by different workers; Claparede calls it "hepatic" pigment, and JoyeuxLaffuie designates the cells as "cellules biliaires." Lankester objects to the above names. He introduced ('97) the name "Chætopterin" for the fluorescent green pigment which is extracted from the intestinal epithelium with alcohol. A comparison of its spectrum with that of chlorophyll led him to correct an earlier statement and say that it is not "chlorophylloid" (Sach's Botany, 2d ed. 1882) but, like the green pigment, "Bonellin," of Bonellia viridis, a metabolic product. He says (page 454), "It is impossible to suppose, in view of the fact that Chætopterus lives in the sand in a large parchment tube, that the intestinal pigment can have any function as pigment. On the other hand, it is not unlikely that it may eventually be shown that this green fluorescent 'Chætopterin' is really representative of the biliverdin of," what the author terms, "vertebrate bile."

Lankester, from Benham's observations, describes the green granules of the intestinal cells as spherical corpuscles varying in size and embedded in the protoplasm of the epithelial cells. He says they are not dissolved by alcohol entirely, but a colorless oily-looking stroma, quite structureless and translucent, of the same shape as the original colored granule, is left in the body. Dr. G. Brandes ('98). on the other hand, regards them as vegetable organisms which live as parasites. He thinks that the "Bonellin" may be identical with the coloring matter of "Chætopterin" but that the differences may be due to some impurities. If these green granules are symbiotic algæ or algæ in the palmella stage, it should be possible to demonstrate it by means of suitable nutrient solutions, as was done by Famintzin ('90) and Beyerinck ('90) for symbiosis in Hydra viridis.

A conspicuous eiliated groove extends within the intestine along its ventral side (Fig. 19), from about the middle of the thirteenth segment (second of the mid-region) till near its posterior end. It is made of tall columnar cells, which contain fewer green granules than the cells of the dorsal and lateral epithelial walls of the intestine. 
These cells bear rather stout cilia at their free ends. The ciliated intestinal groove is not mentioned by any workers.

Vascular and Nervous Systems.-On the blood system I have confirmed Laffuie's descriptions from transverse sections of adult individuals. A peribuccal vessel communicates both dorsally and ventrally with a straight tube located in the median mesenteries which suspend the esophagus. The ventral vessel is a cylindrical or a flattened tube that extends the entire length of the ventral mesentery (Figs. 15-19). I have not observed any transverse branches from the ventral vessel, nor have I studied its posterior communication. The dorsal vessel in the anterior region occupies the dorsal mesentery, but at the posterior border of the anterior region it "spreads out dorsally and laterally and loses its walls." Laffuie claims that the colored fluids injected backward into the dorsal vessel passed out of the vascular space into the body cavity.

Likewise; I verified only from sections the general arrangement of the central nervous system. It consists essentially of a double ganglionic chain which lies beneath the ventral integuments and between the ventral muscles of the middle and anterior regions (Figs. 15-19). Its ganglia, at the level of the segments, are united by delicate cross strands of nerve tissue. Each ganglion gives off a series of from four to ten lateral branches that supply the branches of the parapodia and the skin of the same side. The distribution of these lateral nerves was the basis upon which Laffuie so well worked out the homologies of the segments. Anterior to the ganglion of the twelfth segment the heretofore parallel nerve cords diverge and extend forward along the lateral margins of the ventral plastron to the base of the ventral lip of the buccal funnel. Here each bends dorsally and backward thence, in the dorsal lip, they join over the median line to complete the dorsal loop, or "cerebral band," and the "esophageal commissure" of other annelids.

In the anterior region Laffuie says there are no less than eleven pairs of ganglia. They are united mesially by long parallel fibres which cross the plastron, and externally they give off lateral fibres to the nine setigerous segments, to the eyes and to the antennæ, and thus represent "at least eleven segments" in the anterior region. 


\section{Habits and Physiology.}

Generally speaking, Chætopterus remains wholly confined within its dark brown, parchment-like tube which is embedded in the sand. Although confined within a tube it is not as inactive as its condition would suggest. So long as the tube is submerged in water and the animal is undisturbed it usually keeps a more or less constant current of water traversing its tube. The water serves the double purpose of aeration and of bringing in the supply of food.

The force with which the water is discharged from the tubes of an average size worm is quite considerable. On the shoals I have frequently dropped a pipette full of sand into the incurrent end of the Chætopterus tube before the shoals were completely uncovered. The current ceased almost immediately or was weakly reversed, and, at the end of about a half minute, the animal suddenly expelled the water with such force that it carried the sand to the surface of the water thirty to forty-five centimeters deep. When a larger amount of sand was dropped into the tubes it was expelled after a minute or more. Under these conditions the animal reversed itself in the tube as will be described in a succeeding paragraph.

Through its whole life Chætopterus lives within the same tube or enlargements of its tube, but I cannot agree with Laffuie that "il ne se montre jamais a l'exterieur de son tube." I have frequently seen several segments of the distal end of the worms protruded from the tubes in my aquaria and on the shoals. Two adult specimens that I collected during the summer of 1905 gave evidence, by their regenerating posterior region (in one, all segments back of the third; in the other, a large individual, all the segments back of the fifteenth), that they had protruded a portion of their body at an unfortunate moment. A portion of the "tail" is sometimes exposed above the orifice of the tube when a large quantity of sand, or other irritating matter that has been carried into it, is partly swept and partly pushed out. I have several times seen five or more segments pushed out of the tube and then again withdrawn. This was observed on days when the sand of the exposed shoal had become excessively heated near midday.

While it is quite common to see the buccal funnel just touch the 
periphery of the tube or to protrude slightly from a lateral rent which is formed during the enlargement of the tube, it is rarely seen protruding beyond the orifice. Nevertheless, during a rising tide after an unusually long exposure of the shoals near mid-day one worm protruded the whole anterior region beyond the orifice and again withdrew into the interior. This seems to have represented an effort to avoid the warm water which remained in the tube. A single adult specimen which I collected during the same season had begun to regenerate the portion before the fourth setigerous segment, the one which bears club-shaped black setæ. A new mouth had formed, but it lacked the characteristic thick lips which form quite early in the larva of Chrtopterus. Probably the protruded portions of the worm were bitten off by some passing fish. When these annelids are removed from their tube they may be kept several days in well aerated water without any sign of forming a new tube or any portion of a tube. After they were exposed two days outside of their tubes they began to macerate and soon died even if kept in well aerated water, but several specimens which were transferred to the broadly U-shaped glass tubes in an aquarium of running sea water were kept alive nearly three weeks.

I have reason to believe that the individuals which are kept in the glass tubes continue their normal bodily movements and behave, in general, as they would in their own parchment tubes. The glass U-tubes therefore serve as convenient receptacles for making continuous observations on their habits.

When Chætopterus is placed in a broad U-shaped glass tube about the same size as the parchment tube in which the animal was found, it takes a position in its horizontal portion. Here it lies on its ventral side with the adhesive dises of the twelfth, thirteenth and fourteenth segments attached to the wall of the tube. The notopodia sway back and forth in the water while the neuropodia are in constant rhythmic motion backwards. The distal ends of the notopodia of the twelfth segment are usually joined over the dorsal side, and the thirteenth segment is contracted so that the accessory feedingorgan which it bears is tilted forwards (Figs. 3, 4) till it lies within or immediately back of the arch formed by the union of the noto- 
podia. The three palettes are in rhythmic motion so long as the animal is undisturbed, but when disturbed, as by the addition of carmine or masses of sand, the motion ceases for a time or its direction may even be reversed. Under normal conditions the palettes cause the water to flow over the animal from the anterior to the posterior end. The incurrent end of the tube is therefore nearest the mouth of the animal and the excurrent orifice is nearest the posterior end.

When finely divided carmine in water is permitted to enter at the incurrent end of the tube it is seen that some of its larger particles touch the ventral lip of the buceal funnel and there remain imbedded in the layer of mucus which is extruded. Others pass in the current of water over the dorsal side of the anterior region, thence through the arch formed by the joined notopodia of the twelfth segment; they are then swept around or over the posterior region, and expelled from the excurrent opening. When large granules of carmine or masses of sand are dropped into the incurrent opening the palettes beat only feebly or cause a weak reverse current, as stated above. This response occurs when the sand touches the ventral lip of the funnel or the tentacles. The animal then shrinks backwards in the tube and the palettes vibrate forwards with such energy that the irritating material is expelled to a distance of several centimeters above the "incurrent" end.

When a larger amount of sand and diatoms was added the method of expelling it varied somewhat from that just described. The animal moved slowly forwards toward the incurrent tube. Here it contracted the anterior region and caused its margin to roll dorsalwards so that it took the form of a cylinder. The anterior margin of the buccal funnel and the tips of the tentacles were pushed a few millimeters beyond the periphery of this end of the tube. The body was drawn forwards till it passed the mass of sand. The palettes of the middle region and the neuropodia of the posterior region then began to vibrate rapidly while, at the same time, the body of the worm lengthened backwards. The animal expelled the sand and diatoms, partly by means of the strong current which was produced by the palettes, and in part by the rhythmic movement of 
the neuropodia. The neuropodia transfer the foreign matter backwards from one pair to the next and thence, by extension of the body, push it to the exterior. During this process ten or more of the posterior segments are pushed beyond the orifice of the tube. When the foreign matter is not expelled on the first trial the movements are immediately repeated. After all of the irritating material is expelled the worm takes its normal position in the horizontal portion of its tube and maintains a continuous current of water as it did before the diatoms were added.

Chætopterus may reverse its position in the tube. This is done while the animal is in the horizontal portion of its tube. The ventral lip of the buccal funnel and all the segments back of it successively bend ventralwards and then the whole body moves as though over a pulley situated at this point until the animal is reversed. This would bring the ventral surface of the animal uppermost if it were not righted by a twisting movement of the anterior region as soon as it has been turned under. All the remaining portions of the body are then righted in natural order. When the animal has reversed its position, the sand, which is then beyond its posterior end, is expelled from the tube as has been described above.

The reversal of the current of water follows the reversal in the position of the worm. I have seen this reversal occur twice within an hour in the glass tubes of my aquaria. It is done in from ten to twenty seconds. It may be induced repeatedly by introducing a large amount of sand into the incurrent orifice of the tube.

The animal generally lies in the horizontal portion of its tube, but it may protrude its proximal or distal end at the orifices when it removes objectionable matter and when it repairs or rebuilds the vertical arms of its tube. In all respects, in so far as I have been able to observe, the animals on the shoals, and the two living individuals which I have had under my observation more than nine months in an aquarium, in the laboratory of the Johns Hopkins University, behave like these in the glass tubes.

Even if the uncinal plates of the internal and external lobes of the neuropodia or their modifications, are used exclusively for "holding to the wall of its parchment tube," it is clear that the animal 
can move about in the glass tube with freedom. The rapid vibration of the palettes does not have the tendency of "washing the animal backwards" in spite of the fact that the uncinal plates can not "penetrate the walls" of this artificial tube.

Feeding and the Nature of the Food.-The water which the sedentary annelid causes to pass through its tube bears a large amount of organic matter, and the abundance of the fæces attests to the fact that a large amount of it is strained from the water as it passes over the regions that perform this function.

The fæces, which in an average-sized worm are pretty uniformly six to eight millimeters long and one millimeter in diameter, contain the tests of many of the diatoms which Dr. Caswell Grave ('04) has found to serve as the food of oysters in the same waters. They are principally Melosira, two species, Pleurosigma, Eupodiscus, in addition to other forms which I have not determined. There were also shells of molluscan embryos, skeletons of copepods and young crustacea of several species, but grains of sand are rarely found. It may be true that other embryos have served as food for Chætopterus, but there is no trace in the fæces because of their complete digestion. The presence of eggs of Chætopterus, in sections of the esophagus, leads me to believe that animal cells, when available, likewise serve as food in these annelids.

The general ciliary covering of the large buccal funnel, the grooves of the dorsal surface and the accessory feeding organ of the thirteenth segment of the annelid serve as organs for the prehension of food in the absence of such prehensile organs as are common to many other annelids. This may be demonstrated by the application of finely divided carmine in sea-water to the ciliary grooves. When the carmine is dropped into the grooves of both aliform notopodia of the twelfth segment the small particles are swept downwards toward their bases. Here they pass from each side directly into the ciliary groove of the mid-dorsal line and are swept forwards to its anterior extremity which is directly back of the dorsal lip of the buccal funnel. They are then dropped into the mouth. To this extent my observations agree with those of Laffuie.

The particles of carmine which have traversed the ciliary groove 
to its anterior end usually pass into the mouth by a peculiar muscular contraction. As they reach the anterior end of the ciliary groove the dorsal lip of the buccal funnel is drawn backwards and the ciliary groove, which now extends beyond the dorsal border of the mouth, permits the granules to fall directly upon the ventral lip of the funnel. The dorsal lip is then pushed forward and takes its normal form. Other granules pass from the anterior end of the ciliary groove laterally, along the posterior margin of the dorsal lip of the funnel. Near the mesial side of the tentacles some of the granules are swept over the dorsal lip and into the funnel, others, however, continue laterally posterior to the tentacles and the dorsallydirected auriculate lobes of the ventral lip. They are discarded at the side of the animal in shreds of mucus. Some particles of carmine which had traversed the mesial ciliary groove to its anterioi end were swept to the right and left of the groove and there were swept backwards in two parallel rows to the vicinity of the twelfth segment. Here they were either discarded at the sides of the animal in shreds of mucus or were again swept into the forward current and, thence to the mouth, where they were disposed of as described before.

The particles which dropped upon the ventral lip were swept, indifferently, into the esophagus or towards the margin of the lip and discarded. The statement has been made in another part of this paper that in the accessory feeding organ of the thirteenth segment the granules of carmine are swept from its margin into the deeper portion where they are rotated and mixed with mucus. The accessory feeding organ is tilted so far forwards that it overhangs the mesial ciliary groove when the thirteenth segment, which bears it, is contracted (Figs. 3 and 4). Its muscular lips open widely and the mass of accumulated material is pressed out by contraction and flattening of the whole pouch. The carmine boluses were several times dropped on the mesial ciliary groove. They were then swept forwards to the buccal funnel, but were in each case discarded. One small mass of diatoms which was thus discarded from the accessory feeding organ was swept into the esophagus after it had traversed the mid-dorsal ciliary groove and was dropped on the strong cilia 
of the buccal funnel. This has the appearance of a selective response on the part of the cilia.

The Significance of Mucus.-The presence of mucus in the ciliary currents has been mentioned. Its function in Chætopterus is probably more complicated than that ascribed to it in corals by Dr. Duerden ('06). I also found that the fine granules of carmine could not be dislodged from the surface of the animal by means of a stream from a pipette, but that they continued towards the mouth in shreds of mucus after they have been dropped upon the animal. Some granules in the mucus passed to the mouth but others were discarded. It is generally true that all of the sand is discarded at the side of the animal. Grains of sand are only occasionally found in the fæces.

The mucus aids in forming the fæcal masses in the anterior portion of the digestive tract. Whether they are formed in the short, glandular diverticulum in the dorsal wall of the esophagus (Figs. 16-18), or in the convoluted portion within the twelfth segment, I was not able to determine. The former is about the same length and diameter as the frcal masses and it may be that the matters accumulate in this cavity and are there molded into the form of little cylinders a millimeter in diameter and six to eight millimeters long. The fæcal masses discharged by the worms in my aquarium, after the diatoms had not been agitated for twenty-four to forty-eight hours, consisted chiefly of a shell of yellowish mucus with the same form as those which contain diatoms and other organic matter. The walls of these freal shells bear several parallel spiral markings that make a single turn. They are probably formed when the little masses are pressed out of the dorsal diverticulum into the lumen of the esophagus. Whether the little masses are formed in the convoluted portion in the twelfth segment by constriction of its muscular wall, or in the dorsal diverticulum, is not apparent from my sections, for it must be determined in specimens killed and preserved on the shoals, because the food passes through the animal so rapidly. Throughout the whole of the intestine of the animal the food masses have the same form and structure. They are dark green, nearly black in color. In the dilated portion of the intestine they are tum- 
bled about by the peristaltic movements of its walls. In the narrower portion of the intestine of a well-fed individual from four to six of the food masses lie side by side in the lumen. They are sometimes discharged from the anus singly, but more frequently by twos and threes. The ciliated groove which I described within the intestine probably aids in the movement of the food masses.

The medium in which the animals live normally is heavily charged with food in suspension. In order to make the diatoms of the aquarium available as food for the young worms I agitated the water several times daily. When the water has not been agitated for twenty-four hours or more the fæces which were discharged consisted mainly of the pellicle of mucus with only a few diatoms and the shells of young gasteropods or veligers that breed in the aquaria. An hour after the water has been thoroughly agitated the fæces which are discharged are filled with diatoms. Finely divided carmine that is permitted to enter the incurrent tubes is usually discarded from the tube in less than ten minutes as boluses of red mucus. I have repeatedly dropped these boluses into the tubes for an hour, but they were discharged in each case a few minutes after their entry. Some of the granules of carmine were ingested and then were discharged to the exterior an hour or more after their introduction and the thorough agitation of the water. The finelydivided gelatinous egg-masses of the gasteropods were also rejected in the same way and were not accepted as food.

The amount of fæcal matter discharged and the rapidity of its movements through the animal are proof of the efficiency of the ciliary grooves and the accessory feeding organ as organs of prehension. The water which passes through the tube is strained several times, as, by the cilia of the buccal funnel, the groove of the mid-dorsal side, the complicated ciliary grooves of the arch within the notopodia of the twelfth segment and the cowl-shaped accessory feeding organ of the thirteenth segment.

In the closely related sedentary annelid, Spiochatopterus oculatus (?) the tentacles have undergone a considerable specialization. They have the same form as those of Chætopterus, but they are as long when extended as the body of the annelid. The straight, 
vertically imbedded tube does not permit a constant current of water to pass over the worm. Its pair of long slender tentacles is extended from the orifice of the tube. It scrapes the surface of the diatoms of the aquarium and those which are dislodged are swept up the ciliary grooves to the mouth, which I have never seen above the orifice of the tube. The tentacles further aid in the removal of the fæces to the exterior by means of a reversal of their ciliary vibration.

The perfection of the palettes, correlated with the U-shaped tube, more than compensates for the shorter tentacles, which, in Chætopterus are more primitive than in Spiochætopterus.

The Removal of Excreta.-The cylindrical freal masses are discharged into the horizontal portion of the glass U-tube where the animals lie while feeding. The masses are discharged at intervals of several minutes, but are not swept out of the tube as rapidly as they are discharged from the intestine. They remain till a fairly constant number has been discharged, then the palettes vibrate more strongly and expel them to the exterior. When the small specimens upon which I have made the observation were well fed they expelled from ten to twenty masses at intervals of four minutes.

The fæces are expelled with considerable force by the current of water which traverses the tube. Laffuie's statement that "the fæcal matters owe their density chiefly to the amount of sand in them" is true only in part, as has been stated earlier. The sand grains are usually rejected and expelled from the tube. My observations as described above refute his statement (page 310): "The interior of this tube is never soiled by the fæcal matters, which, if it had occurred, would accumulate in the steepest part and would finally obstruct it completely." "That supports the supposition that. at the moment of expulsion of the fæcal matters to the exterior, the inferior region of the animal which is occupied by the anus, ought to be situated near the orifice of the tube, in such a manner that these matters fall to the exterior."

The Form and Size of the Tubes. - The parchment-like tubes usuaally have the form of a broad $\mathrm{U}$, which is thick-walled and wrinkled in old tubes, but thin and flabby in those recently formed. The 
horizontal portion of the $\mathrm{U}$ is wider than the conical vertical arms that protrude a few centimeters above the substratum. The simple $\mathrm{U}$-form is often modified in tubes that occur in shoals of sand and shells. The arms may here be so constructed that they turn abruptly aside from large shells that may be in their way. Tubes are frequently found with three arms protruding above the sand. These are tubes that have been enlarged by the extension of the horizontal portion and the formation of a new arm (Fig. 2). A septum at the base of the intermediate arm separates its cavity from that of the horizontal portion. I have found intermediate arms with little or no sand, some completely filled, while many have begun to macerate. Every large tube bears the shreds of one or more of these macerated intermediate arms, or the crescentic scars that mark their former union with the newly formed extension. The annulations near the orifices and the longitudinal strips of thinner, sand-covered, parchment alternating with thicker portions of the tubes will be taken up and described in the chapter dealing with the formation of the tubes.

There is great diversity in the size of the tubes. A very young worm formed a characteristic U-shaped tube three millimeters in diameter at its widest portions, and one and three-fourth millimeters at its orifices. The distance between the orifices measured fourteen and one-half millimeters, and the length of the arms (measured from the lower side of the horizontal portion as the base) was sixteen millimeters. During their breeding season I have collected specimens which ranged in length (between the orifices) from six to fifty centimeters, and with arms six to twenty-two centimeters long (vertically).

Size of Specimens Taken from the Tube.-The size of tubes, while it increases considerably with the age of the individuals, can be regarded only as a general index of the size of the annelid which it encloses. One individual which was less than two centimeters long, consisted of fifteen segments in the posterior region. It occupied a tube that measured three centimeters between its orifices. Another specimen, which had eighteen sexual segments, was found in a flabby tube that was three and one-half centimeters long; this 
does not include an incompletely formed horizontal extension of two and one-half centimeters. The annelid itself was nearly five centimeters long. Likewise, among the larger tubes, one that has not been recently enlarged by a lateral extension may contain an annelid of greater length and with a larger number of segments than another tube whose length is greater as a result of such extension.

Size at Maturity.-The smallest specimen in which I found ripe sexual products was the second individual mentioned in the previous paragraph. I am unable to say whether it is a belated individual that was hatched late in the previous season, or one of the precocious individuals of the same season. However that may be, I found three specimens (No. 88, No. 89, No. 90) during the first week in September, 1905, which were about five centimeters long before the lateral extensions were made. They had twenty-five sexual segments, the foremost of which were filled with ripe sexual products as was proven by artificial fertilization of the eggs of the single female with sperm from each of the males. The tubes bore intermediate arms that contained no sand and were very recently abandoned in the formation of lateral extensions that more than doubled their length. (See photograph of No. 89, Fig. 2.) That the largest worms were found filled with ripe sexual products so early as the middle of June, makes it possible that at least these specimens could have grown from eggs and reached maturity in the same season. The development and transformation of the larvæ and the rapid growth of the young worms in aquaria, in spite of a deficient supply of food, confirms the belief that the young worms may, under favorable conditions, reach sexual maturity in the same season. Those which are developed later in the same season reach maturity during the following summer.

\section{Laying of the Eggs.}

The individuals of both sexes are found on the same shoals, and usually from one to three meters apart. The females are more abundant, and constitute sixty per cent of the individuals collected. This association of the sexes warrants the fertilization of a large proportion of the eggs as they are swept about in the currents over 
the shoals. The ripe sexual products, which, as has been stated, fill the general cavity and its diverticula are extruded to the exterior through the nephridial pores of the sexual segments.

I have never been able to observe the egg-laying among the animals on the shoals, but I have observed it in a large individual that had been removed from its tube and placed in a dish of sea-water for the purpose of photographing in strong sunlight. After being in the direct sunlight fifteen or twenty minutes the water became quite warm and the animal began to extrude its eggs. Several hundred eggs had been extruded free into the water when I first observed the phenomenon, and many more were coming from the forward segments of the sexual region. They issued from the nephridial pores during the rhythmic movements of the body. These movements, which are of a peristaltic nature, may have been the means of expelling them, because they came from the pores, after each compression of the segments, in short streams one egg thick. Several thousand eggs were extruded during twenty minutes, after which the animal was killed and preserved. Transverse sections of its sexual segments include eggs in the body cavity. They may also be traced through the nephridia to their pores at the posterior (inferior) surface of the segments (Figs., 4 and 8). Although Laffuie says "the eggs and spermatozoa accumulate in the nephridia where they await the moment for expulsion to the exterior" (italics mine), I have been unable to confirm his statement from sections of nephridia from three of these segments, all of which contained comparatively few eggs in any portion-possibly forty to fifty in each nephridium. Dr. E. A. Andrews (Sept. 20, 1895 ) observed the discharge of a small number of eggs when fresh sea-water had been admitted to an individual kept in a glass U-tube and from this he concluded that they are discharged at high tide, $i$. e., when fresh water is added to that in which they live. I have not been able to verify this nor to determine the conditions that naturally control the egg-laying; whether it occurs after a few eggs have collected in the nephridia, or whether heat and fresh water supply the necessary stimulus. 


\section{Fertilization.}

Mead ('98) made the observation that the "Ripe eggs may be carried in the body-cavity several days before they are laid. During this time neither centrosome nor aster can be distinguished, though the reticulum is unusually distinct. In a few minutes after the eggs have been deposited in sea-water, however, a large number of asters are developed by rearrangement of the cytoplasmic network."

The eggs in the nephridia are to be found in the same stages as those in the body cavity and at no time do they show any sign of an entering spermatozoön or of a male pronucleus. Among the eggs discharged from the animal I found young ones whose germinal vesicles were still intact. The germinal vesicle of these young ova remained intact until the eggs were extruded into the sea-water, then it broke down and the first maturation spindle was formed. These eggs and the ones whose maturation occurred in the body cavity and nephridia may remain in this condition for an indefinite period or until fertilization occurs. The entrance of the spermatozoon, which is of the ordinary tailed form, causes the rapid formation of the polar bodies and female pronucleus, while the male pronucleus is still quite minute and at the distant portion of the egg. The egg at first is spherical and uniformly opaque, but its animal pole becomes flattened and clear at the time that the first polar bodies are formed.

\section{Segmentation, and Formation of the Trochophore.}

The segmentation was studied and correctly described by E. B. Wilson ('83) and Mead ('97). Its external appearance is, briefly, as follows. A few minutes after fertilization a delicate membrane from the oösperm and the polar bodies are extruded, at intervals of a quarter of an hour, from the clear end of the elongated egg.

In its first cleavage the oösperm is divided into two cells of unequal size, by a plane passing through the polar bodies. A large "yolklobe" is formed nearly opposite the polar bodies during the internal changes which accompany the first cleavage furrow. The second cleavage also is meridional and at right angles to the first. The 
four-celled stage passes into the eight-celled stage by division in a horizontal plane. The lower cells are slightly larger than the upper group, but in each group one cell is larger than its neighbors. (Mead calls attention to the left-oblique cleavage in the eight-celled stage of Chrtopterus). The subsequent divisions are nearly synchronous in all the cells to the thirty-two-celled stage and their size, excepting the $\mathrm{D}$ cells, is more nearly uniform than in the earlier stages, some cells divide precociously as there is only a theoretical sixty-fourcelled stage. The embryo becomes elongated somewhat and over its whole surface soon develop cilia that do not penetrate the fertilization membrane. When the embryo is four hours of age the cilia vibrate rapidly and cause it to rotate within the membrane. Although Mead ('97) says the polar bodies are ingested by the rosette cells in the sixty-four-celled stage, I saw the polar bodies attached to the inner surface of the egg-membrane in which a larva was rotating and from which it soon escaped when the wall was ruptured. When five hours old the larva escapes from its fertilization membrane and swims actively at the surface of the water by a rotation of the body on its long axis. At this age the body is ovoid in form and is covered with cilia of uniform length excepting at the broad anterior end where there is a tuft of several longer ones. Eighteen hours after fertilization the close union of the several elongate cilia, and those of the posterior, narrower portion of the body become progressively larger backward. The body becomes more elongate and, when from twenty-one to twenty-four hours of age, the mouth opens at the ventral surface some distance in front of the mesotrochal band of cilia; and a pair of inconspicuous pigment-spots is now seen widely separated on the dorsal side of the body and forward from the mouth. When the larva is twenty-four hours old the mesotrochal band of cilia is stronger and back of it, on each side, is a stout flagellum. The mouth, which appears as a triangular slit, communicates with the alimentary canal. It consists of a transversely-directed esophagus which communicates with the dilated stomach. The stomach opens into a short intestine which is separated from it by a constriction of the walls. The anus is formed on the dorsal side of the body just in front of the posteriorly-directed, 
short protuberance which is commonly referred to as the "terminal papilla."

\section{Further Growth of the Young Trochophore.}

When the young trochophore is about sixty-four hours old it is somewhat spindle-shaped. Its first mesotrochal band of cilia has begun to be atrophied and there remains to represent it only the pair of strong lateral flagella which may be seen vibrating rapidly. At the same time that the first ciliated band is undergoing atrophy a second circle is suggested by a gradual lengthening of the cilia around the region of the body within which is the intestine. Its alimentary canal practically fills all of the body cavity. The mouth has enlarged transversely and its anterior (upper) lip has the form of a lobe. It leads by a spacious ciliated osophagus into the spherical stomach which occupies the middle region of the body. The intestine is a short conical cavity separated from the stomach by a constriction or double fold of the entoderm layer. The intestine does not quite fill the perivisceral cavity posteriorly. Dorsally it opens to the exterior by the anus which is just in front of a "terminal papilla" that bears a tuft of long non-vibratile cilia. Many of the young trochophores have small pellets of diatoms in the stomach at this age.

The larvæ of six days are much like those described, and while they may be kept alive twelve or fourteen days in the aquaria do not seem to thrive. This is due to a lack of proper food in the aquaria, as I would judge from one culture of larvæ that was larger, at five and one-twelfth days, than any larvæ reared during the two previous summers. At this age they had the characters by which it was possible to connect the older larvæ which I reared in the aquaria, with those taken in the tow.

The form of the larva six days old (Text-figures A and B) is either somewhat spindle-shaped or cylindrical according as the body may be changed by muscular activity. It is somewhat longer and more transparent than in the younger specimens. It is covered with cilia which are everywhere of uniform length, excepting in the ciliated girdle around the posterior region of the larva, a pair of 
lateral flagella that really consist of several parallel flagella, and an anterior flagellum. The mouth is a conspicuous large, ciliated, triangular opening surrounded by thick lips. The pre-oral lobe, or upper lip, is larger than in the younger larvæ. It has the form of an overarching hood. The post-oral lobe resembles an inverted harelip. From the narrow posterior end of its $V$-shaped cleft a groove which is provided with strong cilia, that beat towards the mouth, extends backward toward the level of the pair of lateral flagella. The brownish red "eyes" or "eye-spots" are larger and more prominent. The gullet is thick-walled and covered with close-set cilia. It passes obliquely backward and joins the spherical, thick-walled stomach at its antero-dorsal border. The intestine and "terminal papilla" are also longer than in the younger specimens. The swimming is more active and the larvæ are not confined to the surface of the water, but pass frequently to the bottom of the vessels in which they are kept. Many of the specimens of this age, as was also true of the younger ones, had masses of ingested matter in the stomach. The larvæ may, besides the rotation and forward motion, swim rapidly in a circle with the pre-oral lobe and body flexed dorsalwards. They may be kept alive in aquaria for six or seven days longer but do not develop further, in spite of one's effort to feed them on diatom cultures. To this point my observations on the development of the trochophore agree with those which E. B. Wilson made ('83) on larvæ reared from the artificially-fertilized eggs.

That the larvæ may be reared from eggs in aquaria by the use of some suitable method of providing them with animal food is suggested by the rapid growth of a single lot of larvæ during the summer of 1905. Several hundred larvæ that were two days old were transferred to an aquarium containing a luxuriant growth of diatoms (Grave's diatom method) and placed several feet from a window to avoid direct sunlight. When they were six days old the larvæ exceeded in size and development even the oldest specimens of earlier cultures. They were 1 millimeter long as compared with 0.6 millimeter for the dwarfed (and underfed) larvæ reared in earlier cultures. They formed a connecting-link between those just described and the youngest from the tow. The larvæ contained many 
pellets of organic matter in the stomach and intestine. These pellets consisted of small protozoa and other low animals that were abundant in the diatom cultures to which the larvæ were transferred.

These larvæ (Fig. 9) are more elongate, and while not very different in appearance from the underfed larvæ, show some striking differences. There are three pairs of eye-spots; two pairs lateral and one pair in an antero-dorsal position just back of the anterior flagellum which still persists. The additional eye-spot on each side is smaller than, and directly in front of, the one mentioned for the previous stages. (Some individuals had, besides, a row of two or three smaller accessory pigment spots anterior to these.) The anterodorsal pair is seen through the transparent dorsal wall of the esoph-
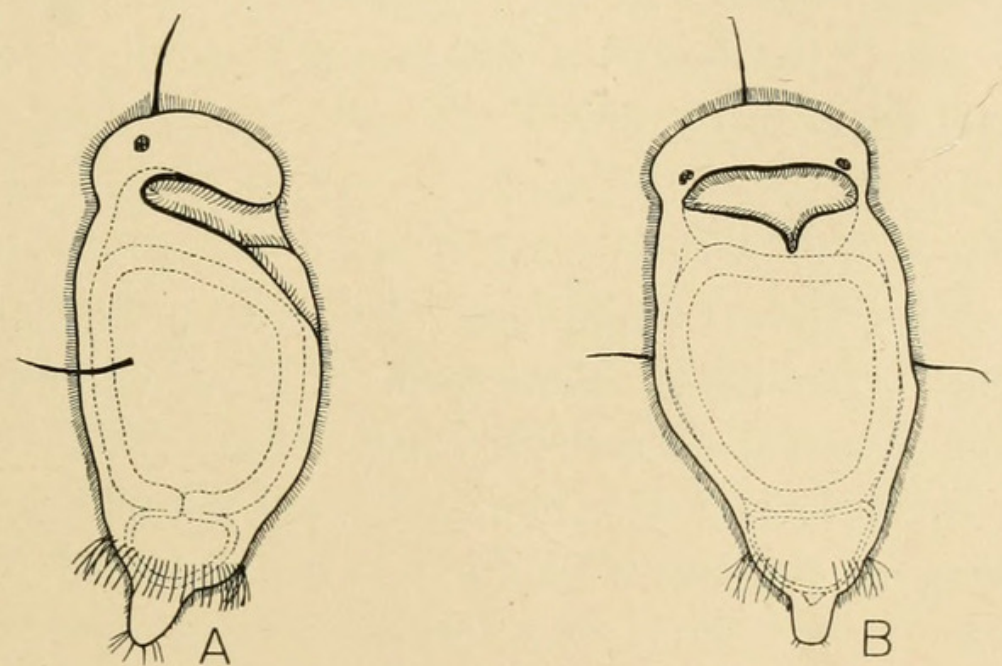

agus. The second band of powerful cilia which, in the earlier stage, was at the level of the middle of the intestine, is now relatively farther forward as a result of the backward growth of the stomach and elongation of the growing-region between the anus and second circle of cilia. The circle of cilia is incomplete for a short space on the ventral side as Wilson observed in larvæ which he reared from the eggs.

The ventral margin of the hemispherical pre-oral lobe has begun to be tilted forwards (anteriorly) so that the mouth now has a greater axial as well as a greater transverse diameter. The free margin of the cleft post-oral lobe is thicker and is turned ventralwards. The esophagus, stomach and intestine have not changed excepting in length. 
The "terminal papilla" is an organ for attachment of the larva which, up to this time, has been pelagic. An individual two days older, which, when placed in water in a watch-glass, swam actively for several minutes, became attached by the free end of its "terminal papilla" to the bottom of the dish. With this point of attachment as a center the larva was seen to swing about in a circle or bend back and forth or from side to side, much as an attached Stentor does. After several minutes I saw the process released and contracted suddenly. Some individuals swam about trailing it in an extended condition as figured by Wilson (Fig. 7, Pl. 2), others used it more or less to aid as a prop in performing creeping movements on the bot tom of the dish. I was unable to rear larvæ beyond this stage in the dishes, but by means of the characters which they possessed I was able to know the larvæ in the tow. The following stages are from material taken in the tow.

\section{Beginning of the Transformation.}

A Chætopterus larva $1.5 \mathrm{~mm}$. long (Fig. 10) is the youngest taken in the tow net. It possesses three pairs of eye-spots and two incomplete rings of powerful cilia directly back of the middle of the body, but the apical tuft and lateral flagella are completely atrophied. The beginning of the transformation is accompanied by a change of habit. The larvæ swim slowly near the bottom of the dish instead of actively near the surface of the water, as is done by the younger ones.

The body of the larva in this stage is fusiform and bears markings on its surface that indicate corresponding regions in the adult. For this reason it will be convenient to refer to the regions as anterior, middle and posterior. The anterior region extends backward to the second (in point of development) ciliary ring, while the middle region includes the two ciliary rings together with nearly all of the remainder of the larva; the posterior region is quite small and inconspicuous at this time. The middle region is the first to become annulated in Chætopterus as it does in the very similar larvæ of the closely related genus, Spiochatopterus, which were more abundant than Chrtopterus in the towings made in August (1905). 
Anterior region.-The anterior region comprises about two-thirds of the larva. It lacks the flagella of the earlier stages and its general ciliation has begun to undergo atrophy. The mouth and the esophagus, however, retain the strong close-set cilia over their surface. The mouth has undergone further axial enlargement by a slight increase in size and further tilting of the pre-oral lobe so that its free ventral margin is nearly in an horizontal plane instead of transverse to the axis of the body. The post-oral lobe, which has increased in length by a growth at its margin, resembles a protruded tongue. The eye-spots on the pre-oral lobe are the same in number and position as in the stage just described (Fig. 10).

Nine short transverse rows of brownish-red pigment spots, on eąch side of the median line, mark off a shield-shaped area on the ventral side of the anterior region between the base of the post-oral lobe anteriorly and the foremost ciliary ring posteriorly. Each line of pigment-spots corresponds with the position of the setæ in the next stage.

Middle region.-The middle region is that portion of the larva which begins with the foremost ciliary ring and ends at the illdefined constriction just anterior to the anus. It consists of two ciliary rings and three more or less clearly defined segments which decrease in size regularly toward the anus.

The ciliated rings are referred to in this paper as "first," "second," and "third" to designate their order of development. The second and third rings consist of a row of powerful cilia on a thickened ectodermal ring that surrounds the widest portion of the body, excepting for a short space on the mid-ventral side of the larva (Fig. 10).

Posterior region.- This region of the larva consists of a very short anal segment to which the growing zone is confined. Its diameter is scarcely more than the anus itself.

The "holdfast" may be regarded as a part of the anal segment from which it is a ventral outgrowth, and into which it is contracted in the transformed larvæ. When the animal is attached to a firm substance, as the bottom of a watch-glass, a considerable degree of agitation of the water is required to detach it. In this, and several 
older specimens, I have seen the "holdfast" extended till it resembled a slender cord nearly as long as the body of the larva. At other times it was contracted to form a thick papilla that was marked with circular wrinkles that suggest annulation, as is shown in a paper by Fewkes. ${ }^{1}$ The hold-fast is indifferently extended or contracted when the animal swims about in the water. It still serves as a prop by means of which the larva may push itself forwards on the bottom of the dish.

When the animal swims rapidly through the water the portion of the body posterior to the ciliated rings is contracted and flexed dorsalwards till the anus rests directly back of the third ciliated ring. The body is then somewhat pear-shaped and the rings of powerful cilia are around the thicker posterior portions. (See Text-figure

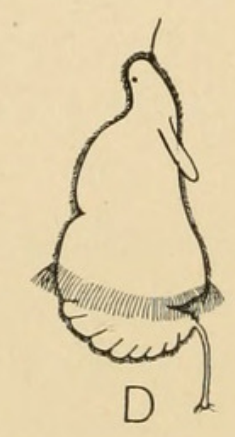

D of Spiochætopterus.) This position of the cilia causes the animal to swim in a wide cork-screw-like path.

Tentacles.-The tentacles appear as a small papilla on each side dorsal to the lateral angles of the mouth and posterior from the lateral eye-spots. In this stage they are covered with fine cilia.

Alimentary canal.- The alimentary canal is shifted forwards and backwards by the muscular contraction of the body, nevertheless it has undergone a considerable permanent change in position.

The esophagus has become a narrow, glandular tube with muscular walls. Anteriorly it opens into the wide, funnel-like mouth, then extends into the median plane of the body to the dorsal wall of the stomach, with which it communicates about the level of the

${ }^{1}$ The "hold-fast" is also shown by figures in papers by Claparede and Metcznikow, M. Müller, Joh. Müller, Beranec, and Wm. Busch. 
sixth or seventh pair of pigmented lines (sixth or seventh setigerous somites). The transverse septa of the setigerous somites extend towards the esophagus as they develop backward from the mouth.

The stomach is shifted backwards so that its foremost ventral wall is at the level of the fourth pair of pigmented lines (fourth setigerous segment), and its hindmost part extends through one or two segments back of the ciliated rings. In several specimens it was observed to occupy chiefly the widest portion of the body-cavity, that within the second and third ciliary rings. It is a spherical sac

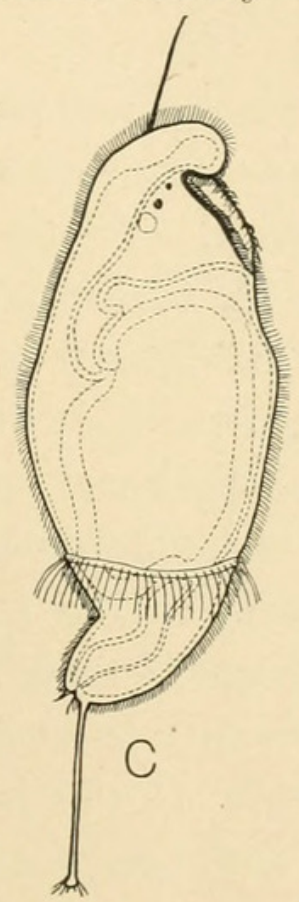

that completely fills the region to which it is confined. Its walls are thick and have a faint tint of green at this age.

The intestine is a nearly straight tube in the mid-ventral line. It communicates with the stomach about the level of the third ciliary ring and opens at the anus which is dorsal to the hold-fast. (See text-figure C of Spiochætopterus.)

Luminosity.-The luminosity that is so striking in the adult is present in all the larvæ of this stage. It is noticeable in the vicinity of the ciliated rings, and is similarly associated with the mucus which the animals discharge into the sea-water. It is still more noticeable.in the older larvæ, in the vicinity of the ciliated rings and the anterior region, when the animals are irritated. 
Transformation from. Free-Swimming to Creeping Larva.

The most advanced larvæ that I have collected resembled the adult worms in the form of the segments and in the transparency of the integuments. These large-bodied larvæ rarely swim about in the aquarium into which they are placed but remain chiefly at the bottom where they move among the diatoms. The parts of the body which correspond with the anterior, middle and posterior regions of the adult are marked off more clearly here than in the earlier stages. The larvæ which correspond with my figures 11, 12 and 13 were 2 millimeters long.

Anterior region.- The anterior region has shared in the growth of the larva and its general appearance has changed considerably as a result of the more rapid growth of some of its parts and the slower growth of others. Thus, its forward end has scarcely increased while the posterior portion has grown in diameter; the plastron has grown so that it is wider than the body; the pre-oral lobe has scarcely increased in size while the post-oral lobe has grown into a large spoon-shaped lip that either hangs downward over the plastron or is directed forwards and kept in the same horizontal plane as the body. This region has undergone a slight dorso-ventral flattening.

The nine setigerous segments have grown so that the foremost ones extend beyond the body of the larva. Septa have appeared between the segments and each segment bears five lance-shaped setre which are like those of the adult. The fourth segment has not yet developed the club-shaped black setæ which are found in the adult condition.

The pre-oral lobe has relatively the same size and form, but is tilted more than in the earlier stage so that its margin now is almost in the same horizontal plane as the animal. It is covered. as in the earlier stages, with cilia that vibrate towards the esophagus.

The greatest increase in size has occurred in the post-oral lobe. It is a large lip that either hangs, apron-like, over the ventral side of the body and covers five or six of the setigerous segments (Figs. 11 and 12) when the larva is swimming, or is directed forward as in the adult worm (Fig. 13) when it is creeping. The auriculate lobes have begun to form by enlargement of its margin near the 
lateral angles of the mouth (Fig. 12). They extend dorsalwards towards the eyes and bases of the tentacles when it is extended forwards. These continue to enlarge until they cover the eyes and the base of the tentacles like in the adult. The post-oral lobe is very contractile, but its lateral edge is usually curved more or less so that the concave side is turned ventralwards when the lobe is flexed, or dorsalwards when extended. This surface is covered with cilia that extend inward and are continuous with those of the gullet.

The tentacles are not so long as the pre-oral lobe. They are directed backwards, like the very much longer ones which are developed earlier in the related genus, Spiochætopterus (Text-figure D).

The five eye-spots, one of which was mesial in position, in the specimen from which Figs. 11 to 13 were drawn, suggests a fusion of the median pair. An individual of the same stage, or slightly older, had a single pair of eye-spots as in the adult. I was unable to determine whether the reduction is brought about through fusion or resorption or whether this was the number originally formed.

A shallow ciliated furrow extends, on the mid-dorsal side of the anterior region, from the anterior convex surface of the pre-oral lobe to the foremost ciliated ring. It increases rapidly in depth after the larva forms its tube, and is well developed in a transformed larva, with four sexual segments, as in any of the mature worms.

Middle region.-This region includes five segments. The foremost two bear the ciliated rings and are of greater diameter than the remaining ones which decrease in size regularly backwards. The whole region is very contractile and its segments may telescope into one another.

The foremost segment of this region, which becomes the "twelfth segment in the adult," bears an incomplete ring of powerful cilia on an ectodermal thickening of its wall. A pair of short antero-posteriorly flattened lobes at the right and left sides of the body is the rudiment of the aliform notopodia. Its position directly back of the thickened ciliary ring suggests that the ciliated groove of the notopodia is a vestige of the dorsal half of this ciliary ring, and that the notopodia are themselves formed by an excessive growth dorsalwards of the right and left sides of the rings. On its ventral side 
where the ciliated ring is interrupted, are two slight mesial thickenings that represent the ventral adhesive disc of the twelfth segment. A pair of similar thickenings on each successive segment of this region indicates the beginnings either of adhesive dises or of neuropodia.

The thirteenth segment is represented in the larva by the hindmost, or third incomplete ciliary ring. On the ventral side is the rudiment of the adhesive disc as mentioned above, and in a mesial position directly back of the dorsal side of the ciliated ring is a bilobed tegumentary outgrowth (Fig. 13) that represents the accessory feeding organ of the thirteenth segment of a transformed larva. Its internal ciliation is possibly derived from a part of the ciliated ring.

The fourteenth, fifteenth and sixteenth segments are somewhat thickened, saucer-shaped dises that decrease in size regularly backwards, and have their convex sides turned forward. They develop into the palettes or "fans," in the transformed worm. Small muscle cells are present in the walls of these segments. They also form cross-strands that unite the forward wall to the rear wall, as is seen in the palettes of the worms. They are not in rhythmic motion in this stage, but are often telescoped into one another by the axial contraction of the larva. The mesial thickening on the ventral side of each segment has been mentioned: the first becomes the small adhesive disc of the first palette, and the others expand into the short, thick neuropodia of the second and third palettes.

Posterior region.-The posterior region is still very small (Figs. 11-13). It consists of two sexual segments, each of which bears a pair of divergent club-shaped to spatulate appendages that extend obliquely backward, and the rudiments of several others, in the form of buds, that are ventral to the anus. Each of the larger divergent appendages encloses a single straight seta of the same form as those found within the conical notopodia of the sexual segment of the adult worm. That these are really the notopodia of the segment, and are formed ventral to the anus but later migrate lateralwards and finally point dorsalwards, is clearly shown in a large worm that was undergoing regeneration of the segments of this region (Fig. 14). In this specimen there were nine segments in various stages of devel- 
opment, from those in which the notopodia and neuropodia ranged from small papillæ on the ventral side, to notopodia and neuropodia of the usual form. In the earliest stage of its development a segment is indicated by a transverse row of four papillæ on the ventral side of the purse-like opening of the anus; forward from these the rows are progressively larger in size and more nearly like the fullgrown structures of the non-mutilated region. The notopodia develop from the outer rows of papillæ, the internal lobes of the neuropodia from the middle pair of papillæ, and the external lobes of the neuropodia appear, first in the second segment from the posterior end, as small buds between the lateral and mesial rows just mentioned. The growth of these papillæ is accompanied with a lateral displacement so that the neuropodia finally occupy a position on the ventral side. and the notopodia on the lateral side of the segments. The pair of oldest notopodia of the regenerating segments, though considerably smaller than those of the uninjured part, has the same shape and is curved outward and backward in a horizontal plane that coincides with that of the body. The second and third pairs are smaller; they diverge, first ventralwards then backwards. The fourth, fifth and sixth pairs are still smaller. They are nearly parallel conical appendages on the ventral side, and between them are the small neuropodia. Back of the sixth pairs they are progressively smaller and lie wholly ventral in position.

The formation of the parapodia is the same in uninjured specimens, excepting that the contracted, or atrophied, "hold-fast" is represented by a small papilla on the ventral side between the anus and the youngest parapodial buds. The growing region is therefore perianal in position.

Digestive tract.- There has been a slight shifting and lengthening of the muscular esophagus till it now opens into the dilated, green stomach near the posterior margin of the plastron. Its walls are ciliated throughout, from the broad buccal funnel anteriorly, to its communication with the stomach.

The stomach is a large thin-walled sac within the twelfth and thirteenth segments, but which bulges forwards into the anterior region and backwards into the first palette. Its walls have a darker 
green color than in the earlier stage just described but less than in the fully transformed larva. This color is undoubtedly due to the same cause as that found in the dilated green intestine of the adult Chatopterus. The intestine is a dilated tube within the palettes but is much narrower in the small posterior region.

Feeding.-The large size and rapid growth of the larvæ are due to their voracious habits. Nearly all the specimens collected in the towings were gorged with pellets of ingested matter. Many of these pellets contained the chitinous skeletons of small copepods, but the contents of others could not be determined because of complete digestion or the absence of skeletal structures.

In order to study their habits of feeding I put one of the oldest larvæ into a small dish of sea-water in which were several copepods, a small planarian, Noctiluca and diatoms. The larva moved along the bottom among the diatoms and when its post-oral lobe (ventral lip) came into eontact with the planarian the mobile pre-oral lobe was pressed down upon it, the cilia vibrated rapidly and the planarian was swept into the buccal funnel. It was then rolled about and rotated several seconds by the cilia and muscular walls of the funnel till it was reduced to a mucus-coated pellet, and was then swallowed by a gulping movement of the muscular esophagus. Less than ten minutes later the same larva captured and swallowed a copepod nearly half its size. The capture was accomplished rather by the movements of the copepod than by any active attack of the Chrtopterus larva. The copepod after moving among the masses of diatoms, suddenly darted to the margin of the spacious buccal funnel; it was swept into this by the cilia and was unable to escape. Another Chætopterus larva swallowed Noctiluca in the same way. Diatoms were also swept into the gullet and swallowed by the oldest larvæ. The cilia of the funnel seem to perform a tactile function, for they discard grains of sand that are taken in with the diatoms. In another instance a metamorphosing pluteus was discharged from the buccal funnel by reversal of the cilia after it had been rotated once or twice. The protruding sharp ends of the skeleton may have irritated the larva and caused the discharge.

Creeping habits.-Before this stage in its development is reached 
the large-bodied larva becomes more sluggish in its movements and settles down, at first becoming attached by the holdfast. Later it creeps among the diatoms of the bottom, with its large post-oral lobe protruded forwards like a scoop. In young specimens the creeping is accomplished chiefly by the movements of the ciliated rings, and the axial contraction of the body, and, in part, by use of the holdfast as a prop; but in older larvæ chiefly by the powerful cilia of the ciliated rings and the greater contractility of the body. When they move among the diatoms of the aquaria they leave a slight trail of mucus. Later they make short, horizontal, mucus-coated tunnels into the mass of diatoms and sand. One of these tunnels may be extended to several times the length of its body and from this simple tunnel of agglutinated sand and diatoms the larva may build the U-shaped tube within which it remains confined.

\section{Formation and Enlargement of the Tubes.}

The first tube in which the larva lives and feeds for several days is nearly a millimeter in diameter and from eighteen to twenty-two millimeters long. It is either a straight tube or a shallow $U$ whose curved portion is downward.

After an interval of a day or two in the mucus-coated tunnel the young worm, for it is now an adult in miniature, has outgrown it and a new tube is constructed. This is done by splitting the tube at a point where the upright arm meets the horizontal portion, in a $\mathrm{U}$-shaped tube, or near one end, in a straight tube, and then excavating a tunnel obliquely downwards and, after nearly doubling the length of the basal portion, upwards to the surface. This is its first lateral enlargement. The sand which the worm excavates is expelled from the opposite end of its first tube. The walls of the tunnel are coated with mucus as the tunnel advances, so that the U-shaped tube is completed when the excavation reaches the surface. The tube becomes strengthened from time to time by additional layers of mucus that harden to form a parchment-like material that gives older tubes a laminated structure. They are enlarged in the same vertical plane as the original tube unless prevented from doing so by some obstruction, as a shell, when they turn obliquely along the surface 
of the obstruction or construct an enlargement from the opposite end of the old tube. Two or three days later the process is repeated, possibly by an extension of the opposite end of the tube. The horizontal portion of each new enlargement is larger in diameter and is buried deeper in the sand than the tube from which it is a branch (Fig. 2). The enlargements are frequently of such length as to double the size of the U-tube, and are completed to the surface of the sand in from twenty-four to forty-eight hours. They are made indifferently at one end or other of the smaller tube. The fate of the intermediate tubes has been discussed in another part of the present paper.

The burrowing is done by the anterior region of the worm. Its setigerous segments dislodge the sand and pass it to the middle and posterior regions of the body, and they convey it backwards into the tube by the combined contraction and expansion of the body, and the rhythmic movements of the palettes and neuropodia. The worm ceases burrowing at intervals of a few minutes and expels the accumulated sand to the exterior in the same way that large quantities are removed by individuals in glass tubes (p. 505). The sand that is removed during the excavation is pushed out of one end of the tube around which it falls and forms a conical mound; the other end, or intermediate tube, is the incurrent tube so long as the burrowing is in progress, but when the new burrow is complete a septum of parchment is formed across the base of the intermediate tube and it ceases to be of any use to the worm.

The worms which form their tubes in aquaria with a thin layer of sand and diatoms on the bottom conform to the U-habit, though in a horizontal plane, with one side of the tube cemented to the floor of the vessel.

The linear extensions are formed at such intervals as the rapid growth of the worm requires. The length of the tubes, and the dates on which the enlargements were completed by two worms which I reared from larvæ taken in the tow-net, are as follows: ${ }^{2}$

${ }^{2}$ Both worms enlarged their tubes to 76 and 71 millimeters, respectively, between September 12, when they were brought to the Biological Laboratory of the Johns Hopkins University, and my return, October 4, 1905. The 
SPECIMEN NO. 2.

Distance

between arms.

$20 \mathrm{~mm}$.

$38 \mathrm{~mm}$.

$60 \mathrm{~mm}$.
Date.

Aug. 7, 1905.

Aug. 10,

Aug. 15,
SPECIMEN NO. 4.

Distance

between arms.

Date.

$20 \mathrm{~mm}$.

$32 \mathrm{~mm}$.

$61 \mathrm{~mm}$.
Aug. 7, 1905 .

Aug. 9, “

Aug. 16, "

Early in September of 1905 I collected three worms whose tubes averaged fifty-one millimeters between the orifices, and five whose recently discarded intermediate arms were sixty millimeters from the ends with which they formed the small U-shaped tubes. The horizontal extensions increased their length to fifteen centimeters in the smallest, and twenty-two and one-half in the longest specimen. Many thick-walled tubes are found with scars of intermediate arms which indicate that they were increased from about this size to forty centimeters. The longest tubes show that they were increased, by a linear extension of ten centimeters, to fifty centimeters.

The tubes also undergo an enlargement in diameter as the animal grows in thickness. This splitting and enlargement of one of its arms I observed in specimen No. 4 during one night in September of 1905 . The worm pushed the rim of its buccal funnel nearly to the margin of the orifice, and slowly moved the ends of the tentacles over the rim of the tube. (In order to enter this narrow portion of the tube from below the edges of the buccal funnel and anterior region of the body were curved dorsalwards and considerably contracted till they became conical in form.) The animal remained in this position in the tube about five seconds, then slowly withdrew into the deeper portion. This was repeated in thirty seconds, but this time it withdrew only to the level of the sand. Here the worm suddenly expanded the first pair of setigerous segments and split the tube longitudinally at its outer side, then withdrew quickly into the deeper portion of the tube. Fifteen or twenty seconds later the worm reappeared at the level of the sand, extended the rent a little

worm in No. 4 extended its tube to the glass wall of the aquarium on May 8-9, 1906. The U-shaped tube now measured 85 millimeters between the orifices. 
higher and again withdrew. This action was repeated five times in extending the rent, seven millimeters, to the end of the tube. The rent was produced by means of the expansion of the muscular, setigerous region and not by the sharp lance-shaped setæ as one might suppose. The rent occurred in a position ventral to the plastron. When the tube was split to its extremity the worm thrust one side of the anterior region through the cleft and removed the sand about it by means of its setigerous notopodia. They pressed a portion of the sand aside, but some was removed backwards into the tube and later discharged at the other end.

When the tube was split to its end the worm spread the basal portion of the rent by a slight expansion of the ventral side of its lower lip and the foremost portion of the anterior region. The worm remained in this position for fifteen or twenty seconds, then withdrew into its tube for half a minute, after which it took a position a little nearer to the orifice of the tube. The performance was repeated till the edges were reunited by a wedge-shaped insertion of parchment that widened to three millimeters just below the level of the sand. I could not determine which region of the body was most active in the secretion of the mucus, which becomes parchment-like, but I observed that it was shaped by the lower lip of the buccal funnel, and that the parchment film had advanced a little higher each time the animal applied its ventral lip to the cleft. The splitting of the tube and the closure of the rent were completed in thirty-five minutes.

The splittings occur indifferently on any portion of the circumference of the tube, but they are found chiefly on the upper side of the horizontal portion. When they are extensive it is indicated by the abundance of sand discharged at long intervals from one arm of the tube. I have found some large tubes which had strips of thin parchment two centimeters wide and as long as the horizontal portion of the tube.

The new portion of the wall is thin and membranous at first and, while it becomes thicker with age, can be observed, long after its formation, as a strip somewhat thinner than the remaining portions of the wall. Its inner surface is smooth, like the inner wall of the other portion, and its outer surface is similarly covered with sand. 
The wide, horizontal portion of nearly every tube bears one or more of these strips inserted between the edges of a thicker laminated wall. This was true even in the smallest specimens, No. 2 and No. 4 , which I mentioned on page 525. The diameter of their tubes was twice enlarged while they were thirty-eight and thirty-two millimeters long, respectively, and before they constructed the next linear enlargement.

The outer surface of the tubes is everywhere coated with sand, excepting about the terminal portions that protrude above the sand flats in which they are imbedded. These terminal portions have one or more annulations that give them the appearance of being formed of rings that diminish regularly in size upwards, so that the bases of the smaller rings are overlapped by the top of the ring next below. Each ring represents the successive height of the orifice, though not its diameter, for they are split from time to time as I have just shown. They are molded, like the other portions of the tube, by the ventral lip of the buccal funnel, and the length of each ring represents the height to which the lip was extended when it was formed. The rings are, at first, very thin and transparent, but they become laminated by successive additions of mucus to their inner walls. The laminæ of which they are the free ends may be separated with ease from those next below.

\section{Summary.}

The species of Chætopterus which is found at Beaufort, North Carolina, is Chcetopterus variopedatus instead of Chcetopterus pergamentaceus of various authors.

The cowl-like structure which is on the dorsal side of the thirteenth somite of the body is an accessory feeding-organ. It is not a "dorsal sucker" as was claimed by Laffuie.

The dorsal diverticulum of the oesophagus is provided with glandular walls. It is of the same length and diameter as the food-masses. It is possible that the food collects in it and is formed into little masses such as are found throughout the intestine.

The intestine is provided, along its dorsal side, with a ciliated groove that extends backward from the ciliated portion to the posterior 
end of the animal. This is probably of use in moving the foodpellets toward the anal end of the intestine.

The annelids, so far as I was able to determine, behave in the parchment-like tubes as they do in glass tubes of about the same size and form.

The eggs and spermatozoa are discharged to the exterior through the nephridia.

The larvæ develop a mesotrochal girdle of cilia which is soon succeeded backward by a second and third ciliary girdle while the mesotrochal band becomes atrophied.

The luminosity which in the adult is associated with the secretion - of mucus is early seen in the larva in the region of the ciliary girdles.

The "terminal papilla" functions as a hold-fast when the larva comes to rest on some submerged solid.

Well-fed larvæ develop three pairs of eye-spots. This was true of all the larvæ taken in the tow-net, but was met less frequently among larvæ reared from the eggs. The presence of this number of eyes led Joh. Müller to name the larvæ "Mesotrocha sexoculata."

The transformation is a gradual one. That portion of the larva anterior to the second and third ciliary rings becomes the anterior region of the worm. It becomes flattened horizontally and the setigerous somites appear at first as a transversely arranged series of pigment-spots on the ventral side. The post-oral lip enlarges enormously and becomes extended forward as the ventral lip of the worm. Green granules like those of the adult occur in the cells of the entoderm in the middle region of even the youngest larvæ collected in the tow-net.

The second and third ciliary girdles mark the first and second somites of the middle region. The former is carried outward by the growth of the aliform notopodia and lines the ciliary furrows of these organs. A portion of the other ciliary girdle persists within the dorsal "accessory feeding-organ." The palettes, the last three somites of the middle region of the worm, are formed by the rapid growth of the dorsal portion of the saucer-shaped somites that lie posterior to the ciliary girdles. This region is succeded by a very 
short anal somite to which the growing-zone is confined. The posterior region of the worm is formed by differentiation of this growing-zone.

The transformation is accomplished by a change of habit. The larva ceases to swim at the surface. It creeps over the bottom where it forms short tunnels the walls of which are made of sand and diatoms cemented together by mucus which is secreted by mucuscells of the body of the larva.

The young worm remains permanently confined within one of these tunnels which it enlarges as often as may be necessary to accommodate its own rapid growth.

The tunnel is enlarged in diameter by being split lengthwise and a new wall is formed in the open space. These tubes are lengthened by the construction of an extension to one end in the form of half of a broad U. Subsequent extensions are made indifferently from one end or other of the base of the old tube. The intermediate arm, which is divided from the main portion of the tube by a transverse septum, becomes macerated and leaves the typical U-shaped tube.

The tubes are made of mucus which is secreted by the body and shaped by the anterior region of the worm. The mucus hardens to a parchment-like consistency.

The rate of growth of the worms is very rapid. Those which develop from eggs laid early in the season reach maturity before the close of the same season.

ZOOLOGICAL LABORATORY,

Purdue University, La Fayette, Indiana.

\section{REFERENCES TO LITERATURE.}

1. Andrews, E. A. Annelids of Beaufort, North Carolina. Proc. U. S. Nat. Mus., Vol. 14.

2. Beraneck, Edou. Quelques stades larvaires d'un Chétoptère. Rev. Suisse de Zool., 1894.

3. Beyerinck, M. W. Culturversuche mit Zoochlorzellen, Lichterengonidien und anderen niederen Algen. Bot. Zeitung, Vol. 48, 1890.

4. Brandes, G. Die Ursache der Grünfärbung des Darmes von Chætopterus. Zeit. f. Naturw., Vol. 70, 1898. 
5. Busch, Wrlh. Ueber die Mesotrocha Sexoculata. Müll. Archiv f. Anat., 1847.

6. Claparede, E., et Metcznikow. Beiträge zur Kenntnis der Entwickelungsgeschichte der Chætopoden. Zeit. f. Wiss. Zool., Vol. 19, 1869.

7. Cosmovici, L. Sur les organes segmentaires et les glandes génitares des Annélides Polychætes Sedentaires. Comptes Rendus de l'Acad. d. Sci. d. Paris, Vol. 88, 1879.

8. Duerden, J. E. The Rôle of Mucus in Corals. Quart. Jour. Mic. Sci., Vol. 49, 1906.

9. Famintzin, A. Beiträge zur Symbiose von Algen und Thieren. Mem. Acad. Imp. Sci., Vol. 38, 1890.

10. Fewkes, W. Bulletin Mus. Comp. Zool., II, Harvard University.

11. Graeffe, E. Arbeiten aus dem Zoolog. Inst. d. Univ. Wien u. d. Zool. Stat. in Triest. Wien, Vol. 15, 1905.

12. Laffute, J. J. Etude Monographique du Chætopterus var. Chætopterus variopedatus. Archiv d. Zool. Exp. et Gen., Series II, Vol. 8, 1890.

13. Lankester, Ray. On the Green Pigment of the Intestinal Wall of the Annelid, Chrtopterus. Quart. Jour. Mic. Sci., New Series, Vol. 40, 1897.

14. Lespes. Etude anatomique sur un Chétoptère. Ann. d. Sci. Nat., Series 5,1872 .

15. Mead, A. D. The Early Development of Marine Annelids. Jour. Morphol., Vol. 13, 1897.

16. Müller, JoH. Bericht ïber einige neue Thierformen der Nordsee. Müll. Archiv f. Anat., 1846.

17. Müller. Max. Ueber die weitere Entwickelung von Mesotrocha Sexoculata. Mïll. Archiv f. Anat., 1855.

18. Quatrefages. Histoire naturelle des Annelés marins et d'eau douce. Paris, Vol. II, 1865.

19. Wrlson, E. B. Observations on the Early Developmental Stages of Some Polychrtous Annelids. Stud. Biol. Lab. Johns Hopkins University, Vol. II, 1883.

20. Enders, H. E. Notes on the Commensals Found in the Tubes of Chætopterus Pergamentaceus. Amer. Nat., Vol. 39, 1905. 


\section{REFERENCE LETTERS FOR FIGURES.}

ac. fd. org., accessory feeding-organ.

ad. d., adhesive disc.

al. not., aliform notopodium.

an., anus.

cil. 2, second ciliary girdle.

cil. 3, third ciliary girdle.

cil. gr., ciliary groove.

cir., cirrus.

dors. div., dorsal diverticulum.

D. V., dorsal vessel.

fl., flagellum.

gl., gland-cell.

hft., holdfast.

int., intestine.

int. neur., internal neuropodium.

l. ey., lateral eye.

med. ey., median eye.

mth., mouth.

neph., nephridium.

neur., neuropodium.

neur $\left\{\begin{array}{l}\text { int. lb., internal lobe of neuropodium. } \\ \text { ext. lb., external lobe of neuropodium. }\end{array}\right.$

ov., ova.

ovy., ovary.

pal., palettes.

pl., plastron.

p. o. l., post-oral lobe or lip.

pr. o. l., pre-oral lobe or lip.

set., seta.

tt., tentacle.

unc. pl., uncinal plates.

vent. nv., ventral nerve.

v. mus., ventral muscle

v. v., ventral vessel.

XII, XIII, XIV, XV, XVI, designate the names of the segments of the middle region of the worm. 


\section{$2 \mathrm{BHL}$ Biodiversity Heritage Library}

Enders, H E. 1909. "A study of the life-history and habits of Chaetopterus variopedatus Renier et Claparede." Journal of morphology 20, 479-531. https://doi.org/10.1002/jmor.1050200306.

View This Item Online: https://www.biodiversitylibrary.org/item/43718

DOI: https://doi.org/10.1002/jmor.1050200306

Permalink: https://www.biodiversitylibrary.org/partpdf/14439

\section{Holding Institution}

MBLWHOI Library

\section{Sponsored by}

MBLWHOI Library

\section{Copyright \& Reuse}

Copyright Status: NOT_IN_COPYRIGHT

This document was created from content at the Biodiversity Heritage Library, the world's largest open access digital library for biodiversity literature and archives. Visit BHL at https://www.biodiversitylibrary.org. 